\title{
How does subchorionic hematoma in the first trimester affect pregnancy outcomes?
}

Taner Günay, Oğuz Devrim Yardımcı

Department of Obstetrics and Gynecology, Medeniyet University Göztepe Training and Research Hospital, Istanbul, Turkey

Submitted: 26 April 2019; Accepted: 3 November 2019

Online publication: 8 January 2021

Arch Med Sci 2022; 18 (3): 639-646

DOI: https://doi.org/10.5114/aoms/113645

Copyright (c) 2020 Termedia \& Banach

\section{Abstract}

Introduction: Subchorionic hematoma $(\mathrm{SCH})$ in pregnancy has been associated with increased risk of adverse pregnancy outcomes. We aimed to investigate the association of $\mathrm{SCH}$ with adverse pregnancy outcomes in pregnant women in relation to size of hematoma and control subjects.

Material and methods: This study included 178 pregnant women with sonographically detected $\mathrm{SCH}$ in the $1^{\text {st }}$ trimester, and 350 pregnant controls without $\mathrm{SCH}$. Data on maternal age, smoking status, gestational week at diagnosis, location of $\mathrm{SCH}$, medications before diagnosis, gestational week at delivery, delivery route and pregnancy outcomes (first trimester vaginal bleeding, pre-eclampsia, gestational diabetes, intrauterine growth restriction (IUGR), placental abruption, preterm delivery < 37 weeks, early pregnancy loss and intrauterine death) were retrieved retrospectively from hospital records. Pregnant women with $\mathrm{SCH}$ were divided into 3 groups according to the size of hematoma including small SCH $(\mathrm{SCH}-\mathrm{I}$ group, $n=47)$, mediumsize $\mathrm{SCH}(\mathrm{SCH}-$ II group, $n=110)$ and large $\mathrm{SCH}(\mathrm{SCH}$-III group, $n=21)$ groups. Results: Subchorionic hematoma was associated with significantly lower gestational age at delivery $(p<0.001)$ and higher rate of first trimester bleeding $(p<0.001)$ compared with the control group, regardless of the size of the hematoma. Placental abruption $(p=0.002)$ and early pregnancy loss $(p<0.001)$ were significantly more common in SCH-II and -III groups than in the control group. SCH-III group was associated with a significantly higher rate of $<37$ gestational weeks at delivery $(p<0.001)$, first trimester vaginal bleeding $(p<0.001)$, early pregnancy loss $(p<0.001)$, IUGR $(p=0.003)$ and preterm delivery $(p<0.001)$ compared to both lesser size hematoma and control groups.

Conclusions: Our findings suggest that large $\mathrm{SCH}$ might indicate an increased risk of adverse pregnancy outcomes such as $1^{\text {st }}$ trimester vaginal bleeding, early pregnancy loss, IUGR, placental abruption or preterm delivery. These findings are important to guide the patients with $\mathrm{SCH}$ for detailed clinical evaluation.

Key words: subchorionic hematoma, pregnancy outcome, size of hematoma, control subjects.

\section{Introduction}

Subchorionic hematoma ( $\mathrm{SCH}$ ) refers to a collection of blood between the chorionic membrane and the uterine wall as caused by the separation of the chorion from the endometrium [1, 2]. It is the most common sonographic abnormality in pregnant women with symptoms of threat-

\author{
Corresponding author: \\ Taner Günay MD \\ Department of Obstetrics \\ and Gynecology \\ Medeniyet University \\ Göztepe Training and \\ Research Hospital \\ Eğitim Mah. Dr. Erkin Cad. \\ 34722 \\ Kadıköy, İstanbul, Turkey \\ Phone: +9(0) 2165666600 \\ Fax: +9(0) 2165666614 \\ E-mail: \\ drtanergunay@gmail.com
}


ened miscarriage and the most common cause of first-trimester bleeding [3, 4]. The incidence of $\mathrm{SCH}$ is considered to range from $1.7 \%$ to $3.1 \%$ in the general obstetric population, whereas it may rise to $20 \%$ in pregnant women with symptoms of threatened abortion $[3,5]$.

Although $\mathrm{SCH}$ is a common abnormality suggested to be associated with adverse pregnancy outcomes such as early pregnancy loss, placental abruption and preterm delivery, the exact impact of $\mathrm{SCH}$ on pregnancy outcomes remains unclear with ongoing controversy regarding the risk of abortion in early pregnancies complicated by $\mathrm{SCH}$ as well as the clinical importance of the size of $\mathrm{SCH}$ in terms of adverse pregnancy outcomes [4, 6-13].

This study was therefore designed to investigate the association of $\mathrm{SCH}$ with adverse pregnancy outcomes in pregnant women in relation to size of hematoma and control pregnant women.

\section{Material and methods}

\section{Study population}

A total of 178 women with singleton pregnancy who had sonographically detected $\mathrm{SCH}$ in the first trimester ( $<14$ weeks) were included in this study conducted between January 2014 and January 2018 in a tertiary care hospital. A total of 350 pregnant women without $\mathrm{SCH}$ comprised the control group. The presence of fetal cardiac activity at the time of $\mathrm{SCH}$ diagnosis was a prerequisite for inclusion in the study, while presence of a nonviable fetus, multifetal pregnancy, fetal abnormality on ultrasonography and pre-gestational diabetes and/or hypertension comprised the exclusion criteria.

Written informed consent was taken from each participant. The study was approved by the Local Ethics Committee of Medeniyet University Göztepe Training and Research Hospital, Istanbul, Turkey.

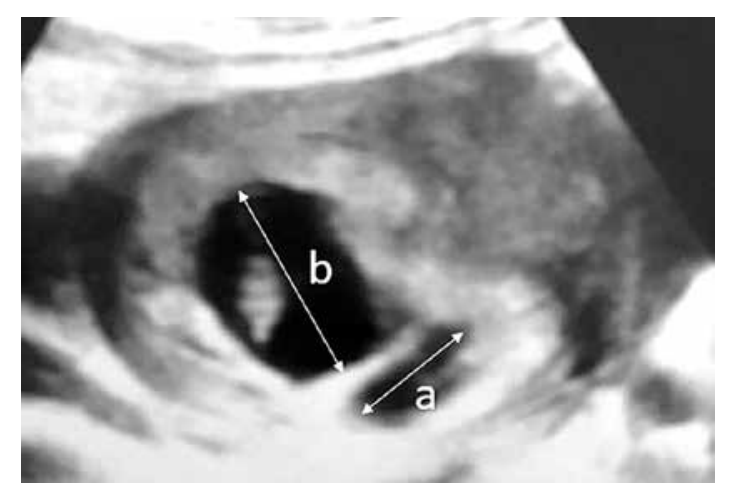

Figure 1. Ultrasound image: 'a' depicting the longest size of the subchorionic hematoma and 'b' depicting the longest diameter of the gestational sac. Subchorionic hematomas were grouped in terms of $\mathrm{a} / \mathrm{b}$ ratios

\section{Assessments}

Data on maternal age, smoking status, gestational week at diagnosis, location of $\mathrm{SCH}$, medications before diagnosis, gestational week at delivery, delivery route and pregnancy outcomes (first trimester vaginal bleeding, pre-eclampsia, gestational diabetes, intrauterine growth restriction (IUGR), placental abruption, preterm delivery < 37 weeks, early pregnancy loss and intrauterine death) were retrieved retrospectively from hospital records.

\section{Subchorionic hematoma diagnosis}

Subchorionic hematoma was diagnosed via transvaginal sonography (SonoScape S11, 2013) in the first trimester in all women by the same obstetrics and gynecology specialist. Pregnant women with $\mathrm{SCH}$ were divided into 3 groups according to the size of hematoma (the ratio of the largest linear diameter of $\mathrm{SCH}$ to the linear diameter of pregnancy sac) including small $\mathrm{SCH}(\mathrm{SCH}-\mathrm{I}$ group, ratio $<1 / 4, n=47)$, medium-size SCH (SCH-II group, ratio $1 / 4-1 / 2, n=110$ ) and large $\mathrm{SCH}(\mathrm{SCH}-\mathrm{III}$ group, ratio $>1 / 2, n=21)$ groups (Figure 1).

\section{Pregnancy outcomes}

Fetal loss was considered either early pregnancy loss (before the $22^{\text {nd }}$ week) or intrauterine death (after $22^{\text {nd }}$ week), depending on the pregnancy week. Pre-eclampsia was defined as new-onset hypertension (two consecutive measurements, at a 4-hour interval, of blood pressure $>140 / 90 \mathrm{~mm} \mathrm{Hg}$ after the $20^{\text {th }}$ week of pregnancy) and accompanying proteinuria $(300 \mathrm{mg} /$ day or +2 proteinuria with urine dipstick or spot urine protein/creatinine $\geq 0.3 \mathrm{mg}$ protein $/ \mathrm{mg}$ creatinine) [14]. Gestational diabetes was defined as diabetes diagnosed during the second half of pregnancy, based on a $50 \mathrm{~g}$ oral glucose tolerance test applied in the $24-28^{\text {th }}$ weeks of pregnancy [15]. Intrauterine growth restriction was defined as fetal weight of < $10^{\text {th }}$ percentile. Placental abruption was detected by the obstetrician at the time of delivery and placental examination. Delivery before the $37^{\text {th }}$ week of the pregnancy was defined as preterm delivery.

\section{Statistical analysis}

Data obtained in the study were analyzed statistically using SPSS 25.0 software (IBM Corporation, Armonk, NY, USA). The conformity of the data to normal distribution was evaluated using the Shapiro-Wilk test, and homogeneity of variance was evaluated with the Levene test. Multiple independent groups of quantitative data (control group and $\mathrm{SCH}$ group) meeting parametric conditions according to age were compared using one-way 
ANOVA. When comparing according to diagnosis and gestational week at delivery, as non-parametric tests, the Kruskal-Wallis $H$ test was used with Monte Carlo simulation technique results, and Dunn's test was used for post hoc analyses. When comparing control and SCH groups (I, II and III) according to parity, gestational week at delivery, first trimester vaginal bleeding, cigarette smoking, route of delivery, early pregnancy loss, IUGR, placental detachment, preterm delivery, pre-eclampsia, gestational diabetes and intrauterine death, the linear-by-linear association and Fisher-FreemanHolton tests were used with the Monte Carlo simulation method, and the column rates were compared with each other and expressed according to the Benjamini-Hochberg adjusted $p$-value results. Multiple ordinal logistic regression analysis was used to determine the cause-effect relationship between explanatory variables (such as gestational week at diagnosis, gestational week at delivery, first trimester vaginal bleeding, early pregnancy loss, IUGR, placental abruption, preterm delivery) and response variables (control and SCH groups). Quantitative variables were stated as mean \pm standard deviation (SD) and median (minimum/maximum) values, and categorical variables as number $(n)$ and percentage (\%) in the tables. Variables were evaluated at a 95\% confidence level and a value of $p<0.05$ was considered as statistically significant.

\section{Results}

Althought not statistically significant, a tendency for association with earlier gestational age at diagnosis was noted in the larger size hematomas (median 8.0 weeks for $\mathrm{SCH}$-III group, 8.3 weeks for $\mathrm{SCH}$-II group and 8.9 weeks for $\mathrm{SCH}$-I group). Subchorionic hematoma was associated with significantly lower gestational age at delivery (median (min-max) 38.29 (8.43-40.71), 37.93 (7.86-40.43) and 27.86 (7.86-37.57) weeks for SCH I, II and III groups, respectively vs. 38.86 (7.14-42.00) weeks in the control group, $p<0.001)$ and higher rate of first trimester bleeding $(21.3 \%, 36.4 \%$ and $76.2 \%$ for $\mathrm{SCH} \mathrm{I}$, II and III groups, respectively vs. $6.0 \%$ in control group, $p<0.001$ ) as compared with the control group, regardless of the size of the hematoma (Table I).

Placental abruption ( $4.5 \%$ and $14.3 \%$ vs. $0.9 \%$, respectively, $p=0.002$ ) and early pregnancy loss $(12.7 \%$ and $42.9 \%$ vs. $3.4 \%$, respectively, $p<0.001)$ were significantly more common in $\mathrm{SCH}-\mathrm{II}$ and III groups than in the control group (Table I).

The SCH III group had a significantly higher rate of $<37$ gestational weeks at delivery $(85.7 \%$ vs. $17.0 \%$ in SCH I, $21.8 \%$ in SCH II and $12.9 \%$ in control group, $p<0.001)$, first trimester vaginal bleeding $(76.2 \%$ vs. $21.3 \%$ in SCH I, 36.4\% in SCH-II and $6.0 \%$ in control groups, $p<0.001)$, early pregnancy loss $(42.9 \%$ vs. $8.5 \%$ in $\mathrm{SCH}-\mathrm{I}, 12.7 \%$ in $\mathrm{SCH}-\mathrm{II}$ and
$3.4 \%$ in control group, $p<0.001)$, IUGR $(23.8 \%$ vs. $2.1 \%$ in $\mathrm{SCH}-\mathrm{I}, 5.5 \%$ in $\mathrm{SCH}-\mathrm{Il}$ and $3.1 \%$ in control group, $p=0.003)$ and preterm delivery (42.9\% vs. $8.5 \%$ in $\mathrm{SCH}-\mathrm{I}, 10.0 \%$ in $\mathrm{SCH}-\mathrm{II}$ and $9.1 \%$ in control group, $p<0.001$ ) as compared with $\mathrm{SCH}-\mathrm{I}$ and II groups as well as with control group (Table I).

No significant difference was noted between study groups in terms of age, SCH localization, medications before diagnosis, parity, cigarette smoking, route of delivery, gestational diabetes, pre-eclampsia and intrauterine death (Table I).

The risk for $1^{\text {st }}$ trimester vaginal bleeding, early pregnancy loss, IUGR, and placental delivery increased with increase in size of $\mathrm{SCH}$, while early pregnancy loss was the parameters associated with the largest increase in risk depending on the hematoma size (Table II).

Apart from higher likelihood of early pregnancy loss in anterior (15.7\%) versus cervical (8.1\%) and fundus $(7.1 \%)$ hematomas ( $p=0.046)$, no significant difference was noted in pregnancy outcomes with respect to hematoma localization (Table III).

\section{Discussion}

Our findings revealed an association of $\mathrm{SCH}$ regardless of the size of hematoma with lower gestational age at delivery and higher rate of first trimester bleeding in pregnant women, whereas increased likelihood of < 37 gestational week delivery, first trimester vaginal bleeding, early pregnancy loss, placental abruption, IUGR and preterm delivery was observed with increase in size of $\mathrm{SCH}$.

The current study was based on subjective evaluation of hematoma size as a fraction of gestational sac size. This seems notable given that amongst the several methods of detecting the size of $\mathrm{SCH}$ reported in the literature this was the method considered to be best correlated with first trimester pregnancy outcome [16].

Our findings are consistent with the previously reported association of presence and/or size of SCH with adverse pregnancy outcomes such as increased likelihood of miscarriage [3-5, 10, 17, 18], IUGR [17], first trimester vaginal bleeding [2, 19], placental abruption [2-4], preterm delivery [2-4] and fetal growth restriction [3, 4].

In a meta-analysis of 7 studies in 1,735 women with $\mathrm{SCH}$ and 70,703 controls, the authors concluded that $\mathrm{SCH}$ was associated with an increased risk of spontaneous abortion (pooled $\mathrm{OR}=2.18$ ) and stillbirth (pooled $O R=2.09)$, abruption $(O R=5.71)$, preterm delivery (pooled $O R=1.40$ ), and preterm premature rupture of membranes (pooled $O R=1.64$ ), but not small for gestational age or pre-eclampsia [7].

In fact, the observation that the $\mathrm{SCH}$-III group had the highest risk of early pregnancy loss in our cohort seems in agreement with data from a past study indicating a cut-off value of $32 \mathrm{ml}$ for the size 
Table I. Comparison of pregnancy outcomes and clinical findings in control and subchorionic hematoma (SCH) groups

\begin{tabular}{|c|c|c|c|c|c|}
\hline Parameter & $\begin{array}{l}\text { Control } \\
(n=350)\end{array}$ & $\begin{array}{c}\text { SCH-I } \\
(n=47)\end{array}$ & $\begin{array}{c}\text { SCH-II } \\
(n=110)\end{array}$ & $\begin{array}{l}\mathrm{SCH}-\mathrm{III} \\
(n=21)\end{array}$ & $P$-value \\
\hline Age [years], mean \pm SD (min./max.) & $\begin{array}{l}27.51 \pm 5.08 \\
\quad(18 / 39)\end{array}$ & $\begin{array}{l}27.04 \pm 5.31 \\
\quad(18 / 39)\end{array}$ & $\begin{array}{l}26.10 \pm 4.88 \\
\quad(18 / 39)\end{array}$ & $\begin{array}{l}27.62 \pm 5.13 \\
(18 / 39)\end{array}$ & $0.094^{1}$ \\
\hline \multicolumn{6}{|l|}{ Hematoma localization, $n(\%)$ : } \\
\hline Anterior & - & $20(42.6)$ & $53(48.1)$ & $10(47.7)$ & \multirow[t]{4}{*}{$0.826^{2}$} \\
\hline Fundus & - & $8(17.0)$ & $17(15.5)$ & $3(14.3)$ & \\
\hline Posterior & - & $10(21.3)$ & $15(13.7)$ & $5(23.8)$ & \\
\hline Cervical & - & 9 (19.1) & $25(22.7)$ & $3(14.2)$ & \\
\hline \multicolumn{6}{|l|}{ Prior medications, $n(\%)$ : } \\
\hline Progesterone & $32(9.1)$ & $7(14.9)$ & $14(12.7)$ & $3(14.2)$ & \multirow[t]{4}{*}{$0.656^{2}$} \\
\hline LMWH & $16(4.6)$ & $2(4.2)$ & $7(6.4)$ & $1(4.8)$ & \\
\hline Aspirin & $6(1.7)$ & $1(2.1)$ & $2(1.8)$ & $1(4.8)$ & \\
\hline None & $296(84.6)$ & $37(78.8)$ & $87(79.1)$ & $16(76.2)$ & \\
\hline $\begin{array}{l}\text { Gestational week at diagnosis, } \\
\text { median ( } \min . / \max . \text { ) }\end{array}$ & - & $8.9(6.1 / 13.9)$ & $8.3(6.6 / 13.3)$ & $8(6.7 / 11.3)$ & $0.094^{3}$ \\
\hline $\begin{array}{l}\text { Gestational week at delivery, } \\
\text { median (min./max.) }\end{array}$ & $\begin{array}{c}38.86 \\
(7.14 / 42.00)^{\mathrm{BC}}\end{array}$ & $\begin{array}{c}38.29 \\
(8.43 / 40.71)\end{array}$ & $\begin{array}{c}37.93 \\
(7.86 / 40.43)\end{array}$ & $\begin{array}{c}27.86 \\
(7.86 / 37.57)^{\mathrm{AB}}\end{array}$ & $<0.001^{3}$ \\
\hline \multicolumn{6}{|l|}{ Gestational week at delivery, $n(\%)$ : } \\
\hline$<37$ & $45(12.9)$ & $8(17.0)$ & $24(21.8)^{A}$ & $18(85.7)^{A B C}$ & \multirow[t]{2}{*}{$<0.001^{2}$} \\
\hline$>37$ & $305(87.1)^{C D}$ & $39(83.0)^{\mathrm{D}}$ & $86(78.2)^{\mathrm{D}}$ & $3(14.3)$ & \\
\hline \multicolumn{6}{|l|}{ Parity: } \\
\hline Primipara & $171(48.9)$ & $25(53.2)$ & $59(53.6)$ & $12(57.1)$ & \multirow[t]{2}{*}{$0.271^{4}$} \\
\hline Multipara & $179(51.1)$ & $22(46.8)$ & $51(46.4)$ & $9(42.9)$ & \\
\hline \multicolumn{6}{|l|}{$1^{\text {st }}$ trimester vaginal bleeding: } \\
\hline Absent & $329(94.0)^{B C D}$ & $37(78.7)^{\mathrm{D}}$ & $70(63.6)^{D}$ & $5(23.8)$ & \multirow[t]{2}{*}{$<0.001^{2}$} \\
\hline Present & $21(6.0)$ & $10(21.3)^{A}$ & $40(36.4)^{A}$ & $16(76.2)^{\mathrm{ABC}}$ & \\
\hline \multicolumn{6}{|l|}{ Cigarette smoking: } \\
\hline Absent & $324(92.6)$ & $44(93.6)$ & $100(90.9)$ & $19(90.5)$ & \multirow[t]{2}{*}{$0.917^{2}$} \\
\hline Present & $26(7.4)$ & $3(6.4)$ & $10(9.1)$ & $2(9.5)$ & \\
\hline \multicolumn{6}{|l|}{ Route of delivery: } \\
\hline CS & $68(19.4)$ & $13(27.7)$ & $25(22.7)$ & $9(42.9)$ & \multirow[t]{2}{*}{$0.065^{2}$} \\
\hline Spontaneous & $282(80.6)$ & $34(72.3)$ & $85(77.3)$ & $12(57.1)$ & \\
\hline \multicolumn{6}{|l|}{ Early pregnancy loss: } \\
\hline Absent & $338(96.6)^{C D}$ & $43(91.5)^{\mathrm{D}}$ & $96(87.3)^{\mathrm{D}}$ & $12(57.1)$ & \multirow[t]{2}{*}{$<0.001^{2}$} \\
\hline Present & $12(3.4)$ & $4(8.5)$ & $14(12.7)^{\mathrm{A}}$ & $9(42.9)^{A B C}$ & \\
\hline \multicolumn{6}{|l|}{ IUGR: } \\
\hline Absent & $339(96.9)^{D}$ & $46(97.9)^{\mathrm{D}}$ & $104(94.5)^{\mathrm{D}}$ & $16(76.2)$ & \multirow[t]{2}{*}{$0.003^{2}$} \\
\hline Present & $11(3.1)$ & $1(2.1)$ & $6(5.5)$ & $5(23.8)^{A B C}$ & \\
\hline
\end{tabular}


Table I. Cont.

\begin{tabular}{|c|c|c|c|c|c|}
\hline Parameter & $\begin{array}{c}\text { Control } \\
(n=350)\end{array}$ & $\begin{array}{c}\text { SCH-I } \\
(n=47)\end{array}$ & $\begin{array}{c}\text { SCH-II } \\
(n=110)\end{array}$ & $\begin{array}{l}\text { SCH-III } \\
(n=21)\end{array}$ & $P$-value \\
\hline \multicolumn{6}{|c|}{ Abruptio placenta: } \\
\hline Absent & $347(99.1)^{C D}$ & $46(97.9)$ & $105(95.5)$ & $18(85.7)$ & \multirow[t]{2}{*}{$0.002^{2}$} \\
\hline Present & $3(0.9)$ & $1(2.1)$ & $5(4.5)^{\mathrm{A}}$ & $3(14.3)^{A}$ & \\
\hline \multicolumn{6}{|c|}{ Preterm delivery: } \\
\hline Absent & $318(90.9)^{D}$ & $43(91.5)^{\mathrm{D}}$ & $99(90.0)^{D}$ & $12(57.1)$ & \multirow[t]{2}{*}{$<0.001^{2}$} \\
\hline Present & $32(9.1)$ & $4(8.5)$ & $11(10.0)$ & $9(42.9)^{A B C}$ & \\
\hline \multicolumn{6}{|c|}{ Pre-eclampsia: } \\
\hline Absent & $324(92.6)$ & $43(91.5)$ & $101(91.8)$ & $19(90.5)$ & \multirow[t]{2}{*}{$0.892^{2}$} \\
\hline Present & $26(7.4)$ & $4(8.5)$ & $9(8.2)$ & $2(9.5)$ & \\
\hline \multicolumn{6}{|c|}{ Gestational diabetes: } \\
\hline Absent & $333(95.1)$ & $45(95.7)$ & $106(96.4)$ & $20(95.2)$ & \multirow[t]{2}{*}{$0.958^{2}$} \\
\hline Present & $17(4.9)$ & $2(4.3)$ & $4(3.6)$ & $1(4.8)$ & \\
\hline \multicolumn{6}{|c|}{ Intrauterine death: } \\
\hline Absent & $348(99.4)$ & $47(100.0)$ & $109(99.1)$ & $20(95.2)$ & \multirow[t]{2}{*}{$0.208^{2}$} \\
\hline Present & $2(0.6)$ & $0(0.0)$ & $1(0.9)$ & $1(4.8)$ & \\
\hline
\end{tabular}

${ }^{1}$ One-way ANOVA test (Robust test: Brown-Forsythe), ${ }^{2}$ Kruskal-Wallis H test (Monte Carlo). Post-hoc test: Dunn's test, ${ }^{3}$ Fisher Freeman Halton test (Monte Carlo), ${ }^{4}$ Linear-by-linear association (Monte Carlo), SD - standard deviation, ${ }^{A}$ significant compared to control group, ${ }^{B}$ significant compared to hematoma I group, ' significant compared to hematoma II group, ${ }^{D}$ significant compared to hematoma III group. CS - cesarean section, IUGR - intrauterine growth restriction.

Table II. Multiple ordinal logistic regression analysis showing pregnancy outcome risk in the SCH and control groups

\begin{tabular}{|lccc|}
\hline Parameter & B & SE & $P$-value \\
\hline Gestational week at diagnosis & 0.169 & 0.061 & 0.005 \\
\hline Gestational week at delivery & -2.911 & 1.916 & 0.129 \\
\hline $1^{\text {st }}$ trimester vaginal bleeding & -2.015 & 0.258 & $<0.001$ \\
\hline Early pregnancy loss & -4.141 & 1.952 & 0.034 \\
\hline IUGR & -1.090 & 0.427 & 0.011 \\
\hline Abruptio placenta & -1.522 & 0.580 & 0.009 \\
\hline Preterm delivery & -3.449 & 1.899 & 0.069 \\
\hline
\end{tabular}

$R^{2}$ (Cox and Snell: 0.221, Nagelkerke: 0.261, Mc Fadden: 0.132), P Model < 0.001. Ordinal logistic regression, B - regression coefficients, $S E$ - standard error, IUGR - intrauterine growth restriction.

of hematoma, with a higher rate of miscarriage for hematomas larger than $32 \mathrm{ml}$ with $81 \%$ sensitivity in ROC analysis [17]. Similarly, in a past study on prognosis of very large ( $>50 \%$ of the gestational sac) first-trimester hematomas, the authors noted the association of very large hematomas with adverse outcome in almost half of the pregnancies along with worse outcomes when the hematoma was diagnosed at an early gestational age [20]. This seems also notable given that larger hematomas were associated with earlier gestational age at diagnosis in our cohort.
In addition, association of presence and size of SCH with an increased risk for preterm delivery but not for intrauterine death in the current study seems consistent with similar rates of intrauterine death reported in pregnant women with and without $\mathrm{SCH}[3]$.

Data from a recent study indicated a higher rate of $\mathrm{SCH}$ in women with risk factors for poor placentation such as multiparity, suggesting the possible association of SCH with poor placentation [21]. Advanced maternal age or increased parity was also found to be associated with $\mathrm{SCH}$ in another 
Table III. Pregnancy outcomes with respect to hematoma localization

\begin{tabular}{|c|c|c|c|c|c|}
\hline Parameter & $\begin{array}{c}\text { Anterior } \\
n(\%)\end{array}$ & $\begin{array}{c}\text { Cervical } \\
n(\%)\end{array}$ & $\begin{array}{c}\text { Fundus } \\
n(\%)\end{array}$ & $\begin{array}{c}\text { Posterior } \\
n(\%)\end{array}$ & $P$-value \\
\hline \multicolumn{6}{|c|}{ Early pregnancy loss: } \\
\hline Absent & $70(84.3)$ & $34(91.9)$ & $26(92.9)$ & $21(70.0)$ & \multirow[t]{2}{*}{0.046} \\
\hline Present & $13(15.7)^{\mathrm{a}}$ & $3(8.1)$ & $2(7.1)$ & $9(30.0)$ & \\
\hline \multicolumn{6}{|l|}{ IUGR: } \\
\hline Absent & $77(92.8)$ & $35(94.6)$ & $25(89.3)$ & $29(96.7)$ & \multirow[t]{2}{*}{0.737} \\
\hline Present & $6(7.2)$ & $2(5.4)$ & $3(10.7)$ & $1(3.3)$ & \\
\hline \multicolumn{6}{|c|}{ Placental abruption: } \\
\hline Absent & $78(94.0)$ & $35(94.6)$ & $27(96.4)$ & $29(96.7)$ & \multirow[t]{2}{*}{0.999} \\
\hline Present & $5(6.0)$ & $2(5.4)$ & $1(3.6)$ & $1(3.3)$ & \\
\hline \multicolumn{6}{|c|}{ Preterm delivery: } \\
\hline Absent & $71(85.5)$ & $31(83.8)$ & $25(89.3)$ & $27(90.0)$ & \multirow[t]{2}{*}{0.782} \\
\hline Present & $12(14.5)$ & $6(16.2)$ & $3(10.7)$ & $3(10.0)$ & \\
\hline \multicolumn{6}{|c|}{ Pre-eclampsia: } \\
\hline Absent & $74(89.2)$ & $35(94.6)$ & $26(92.9)$ & $28(93.3)$ & \multirow[t]{2}{*}{0.841} \\
\hline Present & $9(10.8)$ & $2(5.4)$ & $2(7.1)$ & $2(6.7)$ & \\
\hline \multicolumn{6}{|c|}{ Gestational diabetes: } \\
\hline Absent & $80(96.4)$ & $35(94.6)$ & $27(96.4)$ & $29(96.7)$ & \multirow[t]{2}{*}{0.941} \\
\hline Present & $3(3.6)$ & $2(5.4)$ & $1(3.6)$ & $1(3.3)$ & \\
\hline \multicolumn{6}{|c|}{ Intrauterine death: } \\
\hline Absent & $82(98.8)$ & $36(97.3)$ & $28(100.0)$ & $30(100.0)$ & \multirow[t]{2}{*}{0.787} \\
\hline Present & $1(1.2)$ & $1(2.7)$ & $0(0.0)$ & $0(0.0)$ & \\
\hline
\end{tabular}

study [2]. However, similar to our findings, no significant association of maternal age or parity with presence or size of hematoma in pregnancy was also reported in the literature [17].

Presence of $\mathrm{SCH}$ was also reported to increase the risk of miscarriage in patients with vaginal bleeding and threatened abortion during the first 20 weeks of gestation, but with no significant impact on the outcome measures of ongoing pregnancies such as gestational week at delivery, birth weight, and delivery route [5]. In addition, in a meta-analysis of six studies, the authors confirmed the association of $\mathrm{SCH}$ with an increased risk of spontaneous abortion but not with a significant difference in premature delivery rates and delivery mode as compared with the threatened abortion group [10]. Notably, in our cohort, although the delivery route was similar in study groups, presence of hematoma was associated with delivery at an earlier gestational week compared to the control group, alongside an in- creased risk of earlier gestational age at delivery in pregnant women with larger vs. smaller hematomas. In addition to increased risk of preterm delivery, larger hematomas were also associated with increased risk for placental abruption and IUGR in our cohort. This seems also notable given the suggested association of $\mathrm{SCH}$ in pregnancy with higher likelihood of fetal distress, based on its association with increased risk of operative vaginal delivery (vacuum extraction) or cesarean delivery as well as with higher risk of placental abruption or abnormal placentation compared to pregnancies without SCH [3]. Accordingly, presence of $\mathrm{SCH}$ was also reported to be associated with adverse neonatal outcomes including increased risk of low gestational age at birth, low birth weight, low Apgar score at 1 and 5 min and higher likelihood of admission to the NICU compared to control pregnant women [4].

Indeed, unlike the current study findings, past studies also reported no association of preterm la- 
bor or spontaneous abortion with the size of $\mathrm{SCH}$ $[3,6]$ as well as an increased risk of pregnancy-induced hypertension and pre-eclampsia [2, 3, 21] or gestational diabetes [22] in the presence of $\mathrm{SCH}$. It was also reported that that neither position nor location of the placental hematoma was associated with the pregnancy outcome [20], while a posteriorly located $\mathrm{SCH}$ has been associated more with fetal distress [3]. This seems notable given that localization of the $\mathrm{SCH}$ was similar with respect to size of the hematoma in our cohort.

In addition, while use of low dose aspirin [23], heparin [24] or thrombolytic therapy [25] has been suggested to be associated with an increased risk of developing a SCH during the first trimester pregnancy, our findings revealed no significant difference between $\mathrm{SCH}$ and control groups in terms of progesterone, heparin or aspirin usage rates. Lack of a significant impact of heparin or progesterone therapy on the risk or improvement of early pregnancy loss, respectively, has also been reported in other studies [23, 26, 27].

The exact pathophysiology of $\mathrm{SCH}$-related adverse pregnancy outcomes has not been clearly elucidated, while premature perfusion of the intervillous space, mechanical effects of the hematoma, and impaired angiogenesis causing the hematoma have been suggested amongst the potential predisposing factors [5, 7, 21, 28, 29]. In this regard, albeit not analyzed in the current study, some authors emphasize the potential role of addressing gestational week at miscarriage or fetal distress (Apgar scores) parameters in better understanding of the pregnancy outcomes in women with $\mathrm{SCH}[3,5]$.

\section{Limitations and strength}

The major strength of the current study seems to be assessment of hematoma size with a method best correlated with first trimester pregnancy outcome as well as inclusion of a large cohort of pregnant women with different sizes of SCH and a control group to analyze pregnancy outcomes. However, certain limitations to this study should be considered. First, due to the retrospective single center design of the present study, establishing the temporality between cause and effect is not possible. Second, the lack of data on SCH outcome (persistent or resolved), gestational week at miscarriage, or fetal distress (Apgar scores) is another limitation which otherwise would extend the knowledge achieved in the current study.

In conclusion, the findings of the current study indicate the increased likelihood of adverse pregnancy outcomes in first trimester diagnosis of $\mathrm{SCH}$, including lower gestational age at delivery and higher rate of first trimester bleeding regardless of the hematoma size, but increased likelihood of < 37 gestational week delivery, first trimester vaginal bleeding, early pregnancy loss, placental abruption, IUGR and preterm delivery, particularly in those with larger size hematomas. Our findings emphasize the importance of serial follow-up of pregnant women with $\mathrm{SCH}$ via sonographic examination for the earlier detection of expected adverse pregnancy outcomes such as IUGR and to observe the clinical course of $\mathrm{SCH}$. Further studies addressing the comparison of multiple methods of determining the effect of the size and location of SCH on pregnancy outcomes including the perinatal period might be useful in clinical settings.

\section{Conflict of interest}

The authors declare no conflict of interest.

\section{References}

1. Trop I, Levine D. Hemorrhage during pregnancy: sonography and MR imaging. AJR Am J Roentgenol 2001; 176: 607-15.

2. Norman SM, Odibo AO, Macones GA, Dicke JM, Crane JP, Cahill AG. Ultrasound-detected subchorionic hemorrhage and the obstetric implications. Obstet Gynecol 2010; 116: 311-5.

3. Nagy S, Bush M, Stone J, Lapinski RH, Gardo S. Clinical significance of subchorionic and retroplacental hematomas detected in the first trimester of pregnancy. Obstet Gynecol 2003; 102: 94-100.

4. Hashem A, Sarsam SD. The impact of incidental ultrasound finding of subchorionic and retroplacental hematoma in early pregnancy. J Obstet Gynaecol India 2019; 69: 43-9.

5. Şükür YE, Göç G, Köse O, et al. The effects of subchorionic hematoma on pregnancy outcome in patients with threatened abortion. J Turk Ger Gynecol Assoc 2014; 15: 239-42.

6. Ben-Haroush A, Yogev Y, Mashiach R, Meizner I. Pregnancy outcome of threatened abortion with subchorionic hematoma: possible benefit of bed-rest? Isr Med Assoc J 2003; 5: 422-4.

7. Tuuli MG, Norman SM, Odibo AO, et al. Perinatal outcomes in women with subchorionic hematoma: a systematic review and meta-analysis. Obstet Gynecol 2011; 117: 1205.

8. Mandruzzato GP, D'Ottavio G, Rustico MA, Fontana A, Bogatti P. The intrauterine hematoma: diagnosis and clinical aspects. J Clin Ultrasound 1989; 17: 503-10.

9. Li Q, Zhu J, Hua K. Effects of subchorionic hematoma on pregnancy outcome: a meta analysis. Zhonghua Yi Xue Za Zhi 2016; 96: 1383-5.

10. Johns J, Hyett J, Jauniaux E. Obstetric outcome after threatened miscarriage with and without a hematoma on ultrasound. Obstet Gynecol 2003; 102: 483-7.

11. Fung TY, To KF, Sahota DS, Chan LW, Leung TY, Lau TK. Massive subchorionic thrombohematoma: a series of 10 cases. Acta Obstet Gynecol Scand 2010; 89: 1357-61.

12. Nishida N, Suzuki S, Hamamura $Y$, et al. Massive subchorionic hematoma (Breus' mole) complicated by intrauterine growth retardation. J Nippon Med Sch 2001; 68: 54-7.

13. Johns J, Hyett J, Jauniaux E. Obstetric outcome after threatened miscarriage with and without a hematoma on ultrasound. Obstet Gynecol 2003; 102: 483-7. 
14. Tranquilli AL, Dekker G, Magee L, et al. The classification, diagnosis and management of the hypertensive disorders of pregnancy: a revised statement from the ISSHP. Pregnancy Hypertens 2014; 4: 97-104.

15. International Association of Diabetes and Pregnancy Study Groups Consensus Panel, Metzger BE, Gabbe SG, Persson B, et al. International association of diabetes and pregnancy study groups recommendations on the diagnosis and classification of hyperglycemia in pregnancy. Diabetes Care 2010; 33: 676-82.

16. Heller HT, Asch EA, Durfee SM, et al. Subchorionic hematoma: correlation of grading techniques with first trimester pregnancy outcome. J Ultrasound Med 2018; 37: 1725-32.

17. Ozkaya E, Altay M, Gelisen O. Significance of subchorionic haemorrhage and pregnancy outcome in threatened miscarriage to predict miscarriage, pre-term labour and intrauterine growth restriction. J Obstet Gynaecol 2011; 31: 210-2.

18. Möröy P, Kaymak O, Okyay E, et al. The effects of first trimester subchorionic hematomas on pregnancy outcome. Türkiye Klinikleri J Gynecol Obst 2004; 14: 247-51.

19. Janowicz-Grelewska A, Sieroszewski P. Prognostic significance of subchorionic hematoma for the course of pregnancy. Ginekol Pol 2013; 84: 944-9.

20. Leite J, Ross P, Rossi AC, Jeanty P. Prognosis of very large first-trimester hematomas. J Ultrasound Med 2006; 25: 1441-5.

21. Asato K, Mekaru K, Heshiki C, et al. Subchorionic hematoma occurs more frequently in in vitro fertilization pregnancy. Eur J Obstet Gynecol Reprod Biol 2014; 181: 41-4.

22. Tower CL, Regan L. Intrauterine haematomas in a recurrent miscarriage population. Hum Reprod 2001; 16 2005-7.

23. Truong A, Sayago MM, Kutteh WH, Ke RW. Subchorionic hematomas are increased in early pregnancy in women taking low-dose aspirin. Fertil Steril 2016; 105: 1241-6.

24. Lee RH, Goodwin TM. Massive subchorionic hematoma associated with enoxaparin. Obstet Gynecol 2006; 108: 787-9.

25. Usta IM, Abdallah M, El-Hajj M, Nassar AH. Massive subchorionic hematomas following thrombolytic therapy in pregnancy. Obstet Gynecol 2004; 103: 1079-82.

26. Coomarasamy A, Devall AJ, Cheed V, et al. A randomized trial of progesterone in women with bleeding in early pregnancy. N Engl J Med 2019; 380: 1815-24.

27. Fijałkowska A, Szczerba E, Szewczyk G, et al., ZATPOL Registry Investigators. Pregnancy as a predictor of deviations from the recommended diagnostic pathway in women with suspected pulmonary embolism: ZATPOL registry data. Arch Med Sci 2018; 14: 838-45.

28. Jauniaux E, Watson AL, Hempstock J, Bao YP, Skepper JN, Burton GJ. Onset of maternal arterial blood flow and placental oxidative stres. A possible factor in human early pregnancy failure. Am J Pathol 2000; 157: 2111-22.

29. Hertzberg BS, Middleton WD. Placenta, umbilical cord, and cervix. In: Ultrasound: The Requisites. $3^{\text {rd }}$ ed. Elsevier Health Sciences 2015; 469-95. 